The effect of crowd removal on goal scoring in professional football David J Harris ${ }^{1}$, Mark R Wilson ${ }^{1}$, Samuel J Vine ${ }^{1}$

1: School of Sport and Health Sciences, University of Exeter, Exeter, UK, EX1 2LU D.J.Harris@exeter.ac.uk, Mark.Wilson@exeter.ac.uk, S.J.Vine@exeter.ac.uk

Correspondence concerning this article should be addressed to Dr David Harris, School of Sport and Health Sciences, University of Exeter, St Luke's Campus, Exeter, EX1 2LU. Contact: D.J.Harris@exeter.ac.uk. ORCiD: https://orcid.org/0000-0003-3880-3856 
Running head: FOOTBALL CROWDS

This manuscript has not been peer reviewed

\section{The effect of crowd removal on goal scoring in professional football}

\section{Introduction}

One striking difference between elite sport and recreational sport is that elite sportspeople are accustomed to performing in the spotlight. Many high-level sports are played out in front of large crowds, who can themselves exert an effect on players and officials (Boudreaux et al., 2017; Downward \& Jones, 2007; Epting et al., 2011). For instance, the presence of a crowd, even a small one, may exert a social facilitation effect, where merely being observed by, or in the presence of, another person modifies performance (Strauss, 2002; Triplett, 1898; Zajonc, 1965). Social facilitation can lead to performance improvements through increased motivation/drive or disruptions through distraction or attentional overload. However, in a review of empirical findings for social facilitation, Strauss (2002) reports that, for motor tasks at least, effects are weak at best. Alternatively, crowds may impact performance through external motivation (Paulus, 1983) as well as cause increases in arousal, which again may be beneficial or detrimental (Jones et al., 2007; Jones, 2003).

As high-level sporting encounters are dependent on audiences for income generation it is rare that they occur without a crowd, although it does happen on occasions, such as for security reasons. The COVID-19 pandemic in 2020 has impacted sport and exercise in many ways, but it does present a rare opportunity to examine the effect of crowds, or the lack thereof, on elite sport. There is a precedent for this approach; a measles epidemic prevented crowds at basketball games in a North American basketball conference in 1988-89. Moore and Brylinsky (1993) studied the effect that this had on the performance of teams in the league. The authors reported an increase in points scored, as well as improved field goal and free throw percentages, suggesting the absence of the crowd provided some benefits for players (in an attacking sense at least). Anecdotally, it seems that several sports are seeing more high scoring games since the prevention of crowds in the wake of the COVID-19 pandemic. This appears to be the case for American Football in the NFL (a roughly 20 percent increase in the average score compared to games since 2000; New York Times, 2020) and may also be true for soccer in the English Premier League (TalkSport.com, 2020). 
Running head: FOOTBALL CROWDS

This manuscript has not been peer reviewed

A mechanism that may explain the reported benefits for basketball players observed during the measles epidemic (Moore \& Brylinsky, 1993) is a reduction in psychological pressure from the removal of crowds. Psychological pressure can impair the performance of motor tasks via the negative emotional state of anxiety, and the resultant increase in distraction or self-focus (Beilock \& Carr, 2001; Eysenck \& Wilson, 2016; Hill et al., 2010; Nieuwenhuys \& Oudejans, 2012; Payne et al., 2018). For instance, the presence of a crowd could increase a performer's fear of failure if they expect to get booed for making a mistake (Eysenck \& Wilson, 2016). Indeed, it has been observed that performance of away teams is inhibited immediately after spectator booing (Greer, 1983). Even home field audiences may actually be detrimental when results are more critical or pressurised (Baumeister \& Steinhilber, 1984). Wallace, Baumeister, and Vohs (2005 p. 429) have argued that supportive audiences lead performers to "avoid failure rather than seek success", which, in many cases, may induce performance decrements. Indeed, Butler and Baumeister (1998) have shown that, for more difficult tasks, individuals perform less well in front of supportive audiences than unsupportive audiences (but see also Marcelino et al., 2009). Therefore, even a supportive crowd may exert an additional pressure on athletes. Consequently, the removal of that pressure could lead to performers executing skills more effectively. It seems likely that highly skilled aspects of attacking play in many sports, like free throw and field goal shots in basketball, might be particularly prone to the effects of pressure which could explain the increase in scoring.

In the present work we sought to use the rare opportunity to compare professional sport without a crowd with typical performance from previous seasons. We focused on the English Premier League as, anecdotally, there appears to have been an increase in goal scoring. Our primary aims were to: 1 ) determine whether more goals are in fact being scored; and 2) if so, further explore whether any performance data can indicate why this might be the case. Based on theories of sporting pressure/anxiety (Baumeister, 1984; Eysenck \& Wilson, 2016; Nieuwenhuys \& Oudejans, 2012; Wallace et al., 2005) it was expected that an increase in goals resulting from the removal of crowds might be explained by better execution of attacking skills, rather than a general change in effort or a reduction in the effectiveness of defending. 
Running head: FOOTBALL CROWDS

This manuscript has not been peer reviewed

\section{Method}

This study adopted an observational design, taking advantage of the naturally occurring independent variable of crowd presence which changed from pre to post COVID19. The benefit of this approach is that a large real-world data set from elite sport can be studied in a way that would not otherwise be possible. This is an approach that has been used previously to examine the effects of prior results, match conditions and situational pressure in elite sport (Deutscher et al., 2018; Harris et al., 2019; Hickman \& Metz, 2015; Toma, 2017). The disadvantage of this approach is the difficulty with measuring and inferring mechanisms, a limitation of the work the we discuss in detail.

To examine changes in goal scoring across previous seasons of the English Premier League, individual game results were obtained from https://www.footballdata.co.uk/englandm.php. In order to most closely match the games across seasons, the first [38] games from each season were selected, to reflect the number of games that had been played in the $2020 / 21$ season at time of writing. Additionally, more detailed statistics on gameplay (e.g. shots on target, possession, pass accuracy) were retrieved from www.whoscored.com. Unfortunately, this data set did not allow for game by game statistics, only season by season averages. Hence when using this more detailed data set we compared the $2020 / 21$ season to previous season that have been completed in front of crowds (i.e. not the $2019 / 20$ season which ended with no crowds). The data set included a range of metrics related to goals scored, the positions they were scored from, shots taken, dribbling/passing/tackling success, and is available online [OSF link].

\section{Data analysis}

Data analysis was conducted in R Studio ( $R$ Core Team, 2017). A repeated measures ANOVA with Bonferroni-Holm corrected t-tests was used to test the hypothesis that goals have increased in the early part of the $2020 / 21$ season, compared to previous years. Next, we conducted a series of exploratory analyses on the more detailed statistics to examine potential mechanisms. As these analyses were truly exploratory and not aiming to test any specific hypotheses, no null-hypothesis tests were run (Lakens, 2019; Scheel et al., 2020). Instead, these analyses primarily took the form of graphically representing differences in the data (Allen et al., 2019; Patil, 2018). Additionally, we have provided effect sizes and Bayes 
Running head: FOOTBALL CROWDS

This manuscript has not been peer reviewed

92

\section{Results}

\section{Goals}

First, we examined whether there were more goals in the current, no-crowd, season (2020/2021) compared to the previous four seasons. This data was based on the first 38 games of each season. A repeated measures ANOVA indicated a significant main effect of season, $F(3.65,69.30)=6.69, p<.001, n_{p}^{2}=0.62$. Bonferroni-Holm corrected pairwise comparisons indicated that there were significantly more goals in the 2021 season, than all other seasons ( $p s<.015)$. There were no other significant differences between seasons (see figure 1).

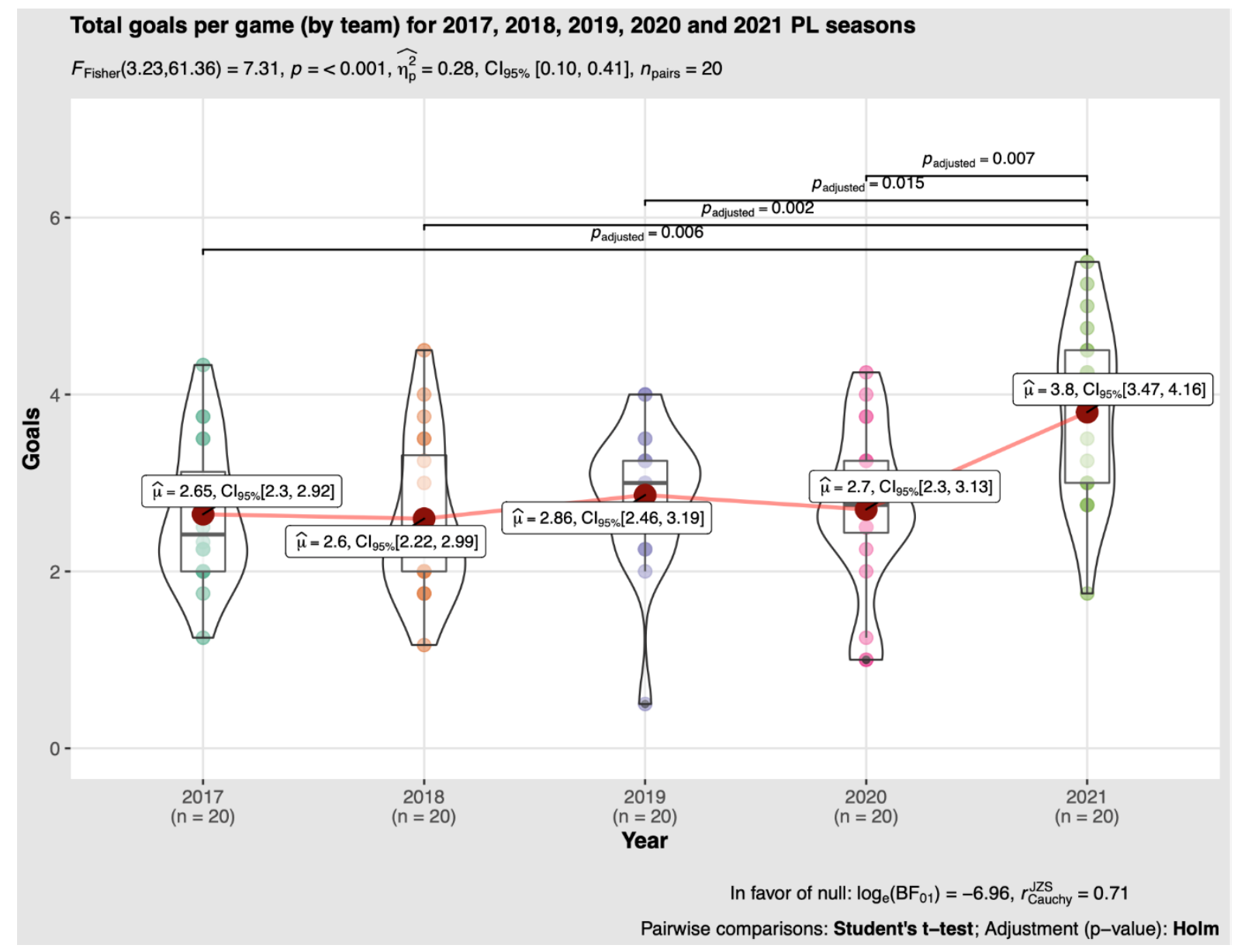

Figure 1 - Goals per game by team average for 2017 to 2021 seasons, based on the first 38 games of each season. Box and violin plots are displayed with mean (red circle) and median (grey bar) for each season. 
Running head: FOOTBALL CROWDS

This manuscript has not been peer reviewed

107

108

109

110

111

112

113

114

115

116

117

118

119

120

121

122

123

124

125

126

127

\section{Mechanisms}

As it was confirmed that significantly more goals are being scored in the no-crowd 2020/21 season, we next aimed to explore more detailed statistics about game play. As we were only able to obtain whole season data for these additional metrics we compared the $2020 / 21$ season to date with two previous full seasons that were completed in the presence of crowds (2017/18 and 2018/19).

\section{Types of goals scored}

First, we explored the types of goals that were being scored. In relation to the location the goal was scored from, Figure 2 indicates that there was no increase in goals scored from outside the penalty box (panel C), or from inside the six-yard box (panel A). However, there was a clear increase in goals from inside the penalty box (excluding six-yard box; panel $\mathrm{B}$ ), which was supported by $\mathrm{BF}_{01}=6.98$ for the main effect. There was also visibly higher variance for the current season, which reflects that the data relates to fewer games.
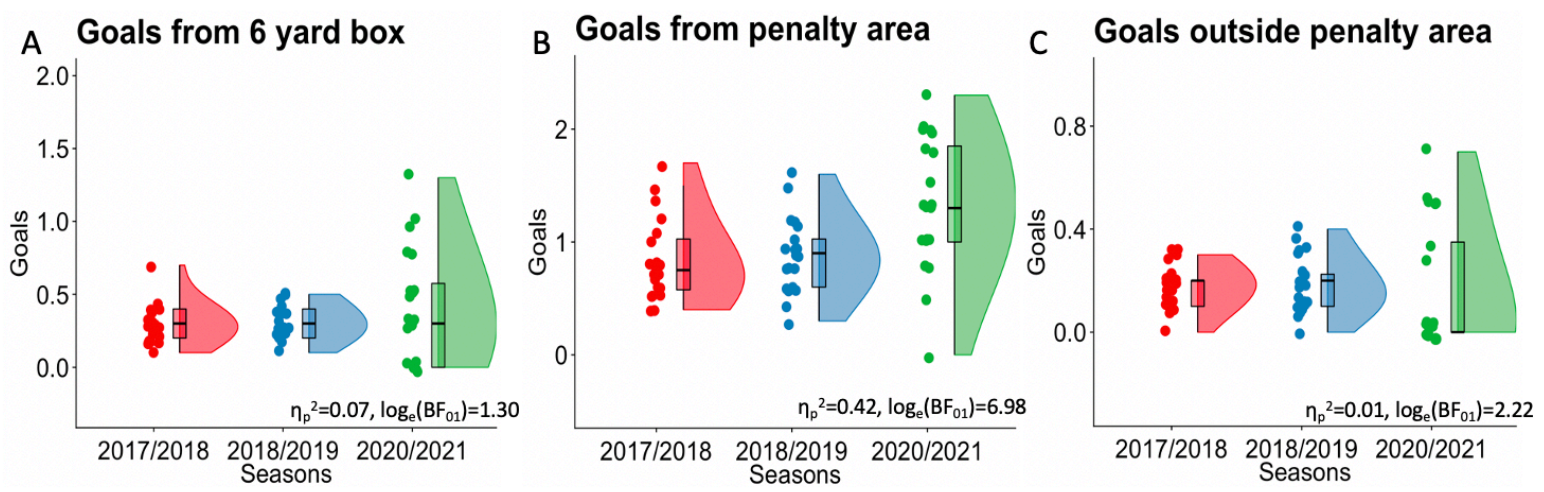

Figure 2 - Raincloud plots (raw data, boxplot, and distribution) showing average number of goals scored from within the 6 yard box (A), from the penalty area excluding the 6 yard box (B) and scored outside the penalty area (C) for each team in the premier league (i.e. each data point is a team).

Additionally, figure 3 indicates that there was a small increase in goals from open play and a clear increase in goals from penalties $\left(\mathrm{BF}_{01}=5.03\right)$. In contrast, there was no obvious increase in goals from counter-attacks or set pieces (i.e. corners, free kicks). 
A Goals from open play

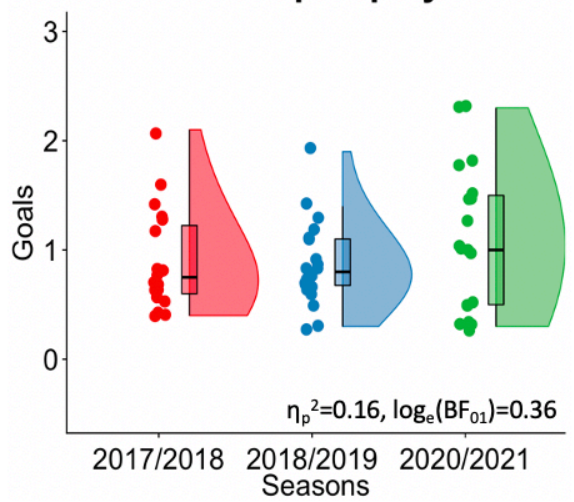

C Goals from penalties

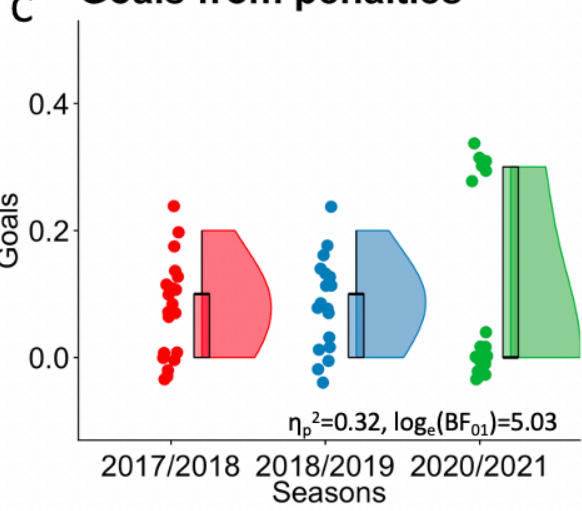

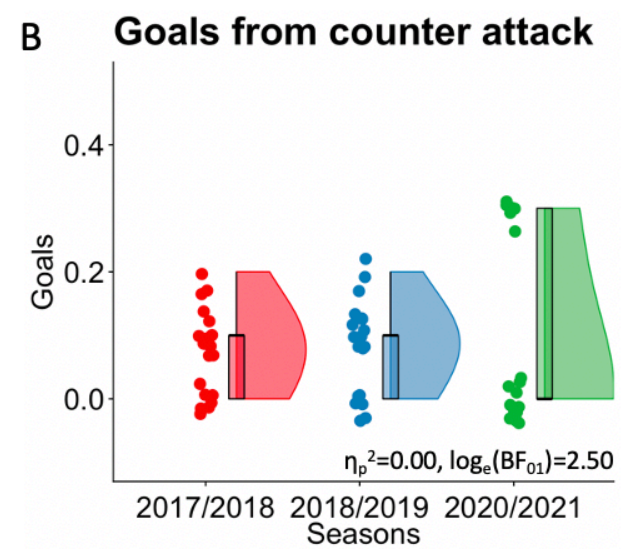

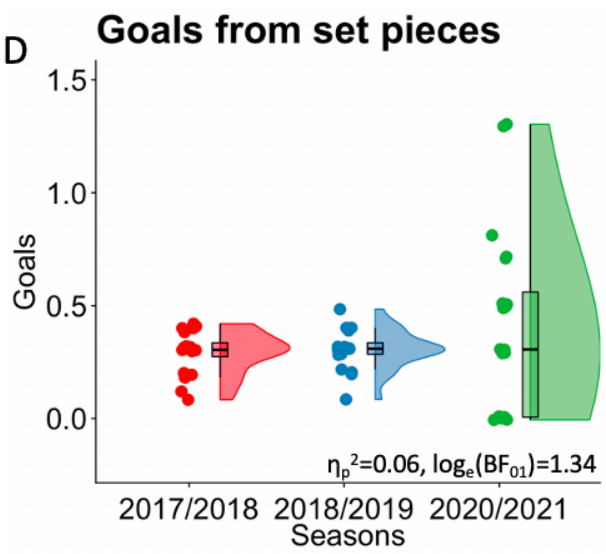

Figure 3 - Raincloud plots showing average goals scored from open play (A), counter attacks (B), penalties (C) and set pieces (D) per team.

\section{Attacking/risk taking play}

As researchers have suggested that pressure can affect risk taking (Wallace et al.,

133 2005), we first explored whether the removal of crowds had led to more attacking play that

134 might indicate more risks were being taken. We examined interceptions per game, which

135 may indicate riskier passing, as well as shots taken and dribbles made, which indicate

136 attacking play. The plots in figure 4 indicated that there was no clear differences for any of

137 these metrics for the current season. If anything, fewer shots are being taken. Based on

138 these metrics there is no indication that play has been more attacking. 
A Shots taken per game

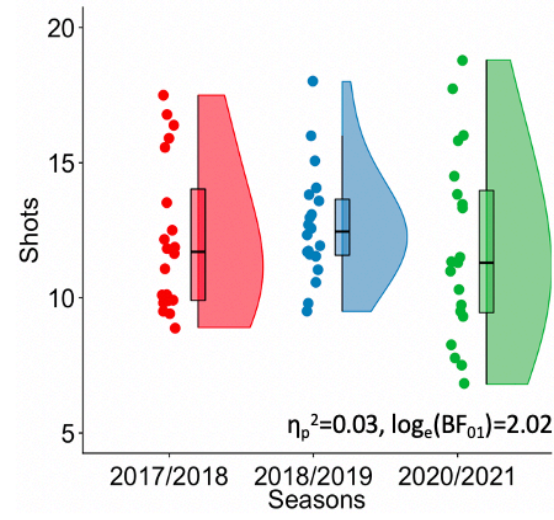

B Interceptions per game

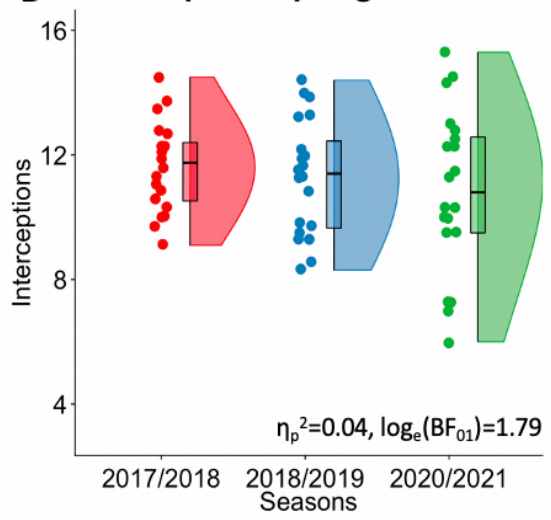

C Dribbles per game

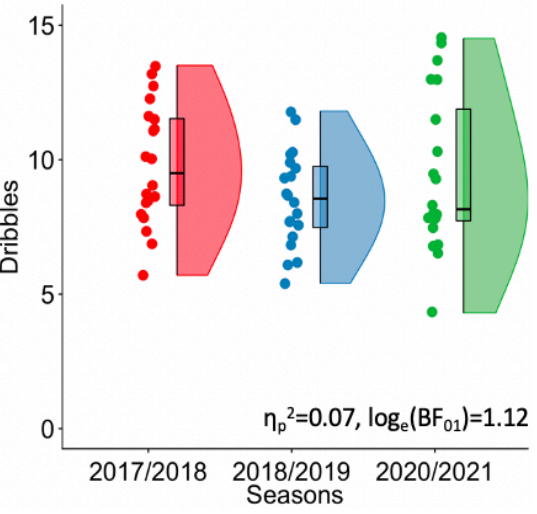

140 Figure 4 - Raincloud displaying average shots taken (A), interceptions given up (B) and

141 dribbles made (C) for each team in the premier league.

Skill execution

Based on the previous findings from basketball (Moore \& Brylinsky, 1993), and

theories of sporting pressure (Baumeister, 1984; Eysenck \& Wilson, 2016) it was

145 hypothesised that the removal of pressure might improve the execution of some skills. In

146 particular we examined whether passing accuracy (\% complete), dribbling success (number

147 successful per game), number of shots on target and shooting accuracy (ratio of on target

148 shots to total shots) varied across seasons. Figure 5 suggests that there was no compelling

149 evidence that players were executing skills more effectively. There was a slight

150 improvement in shots on target (panel C) and shooting accuracy (panel B), but the

151 differences were small. There was no change in passing accuracy or dribbling success

152 (although panel D indicates that dribbling success was particularly low for the 2018/19

153 season). 
Running head: FOOTBALL CROWDS

This manuscript has not been peer reviewed
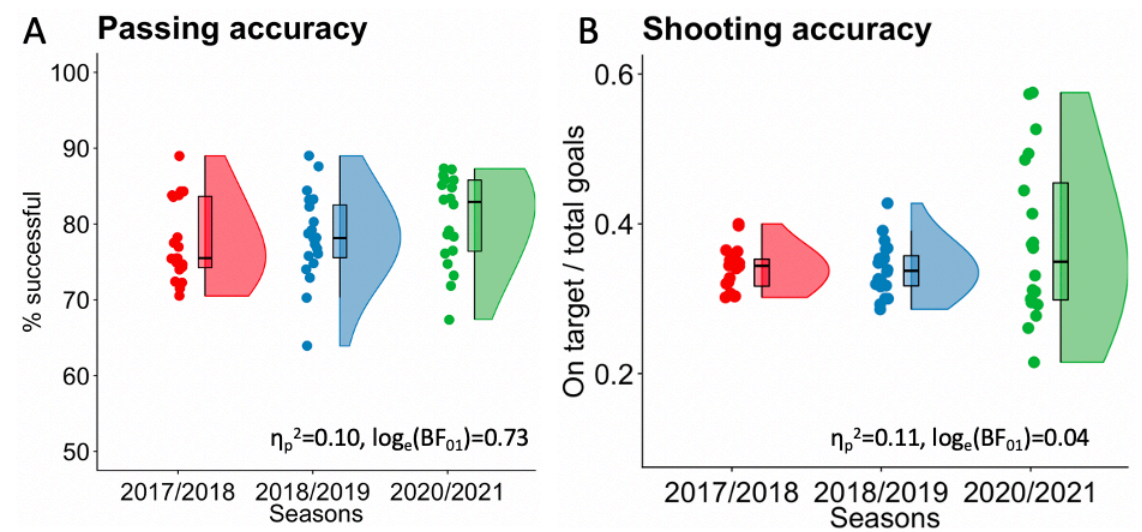

C Shots on target per game

D Dribbling success
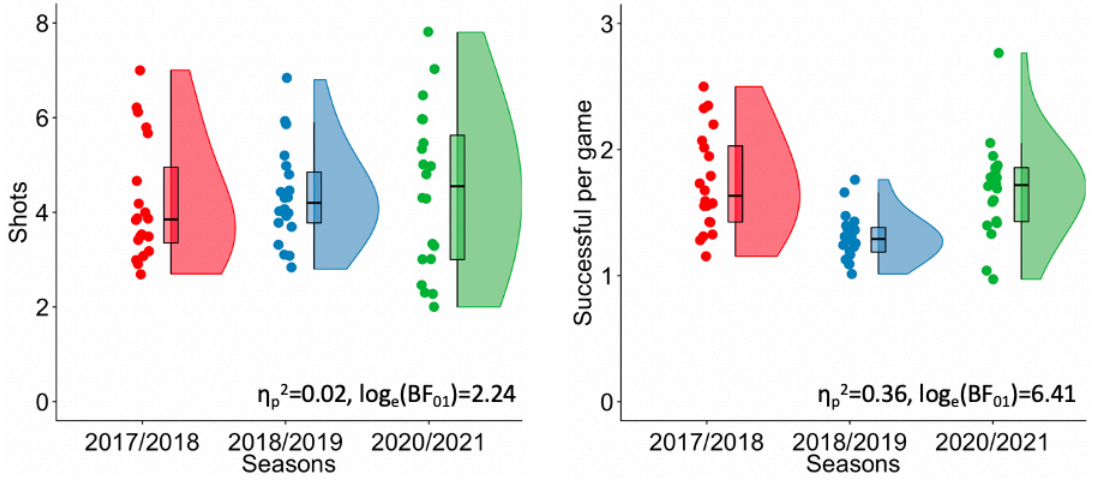

Figure 5 - Raincloud plots of passing accuracy \% (A), shooting accuracy (ratio of on target to total) (B) shots on target (C) and dribbling success (D).

\section{Defensive play}

As attacking play was not demonstrably better, we next examined defensive

159 statistics to explore if the increase in goals was a result of poorer defensive play. The plots in

160 figure 6 indicated that there were possible decrements in the number of tackles (panel A),

161 number of clearances made (panel B) and number of crosses blocked per game (panel D),

162 but no change in shots blocked. However, for clearances and crosses there was perhaps

163 already a downwards trend from the previous year. 

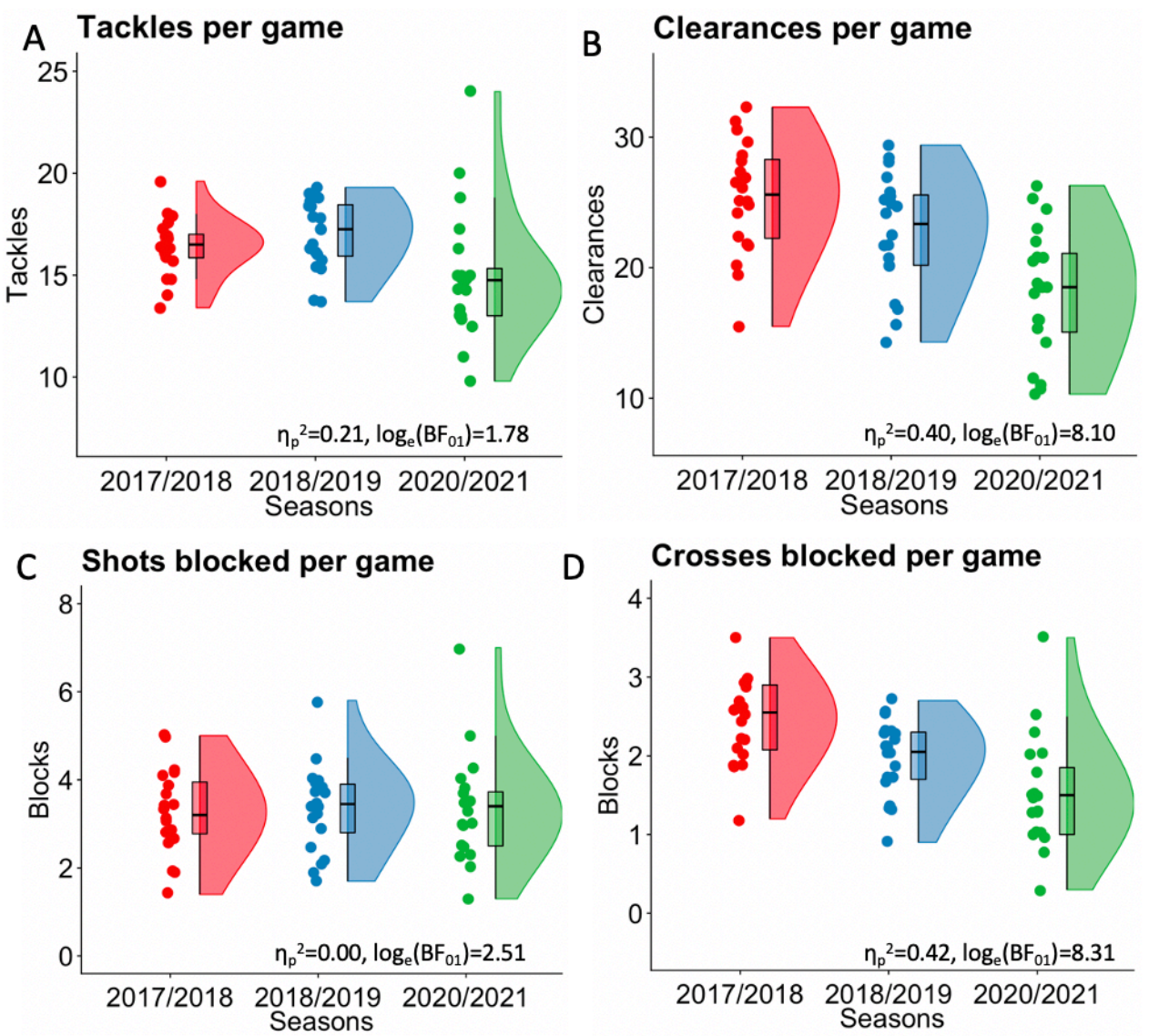

Figure 6 - Raincloud plots of average tackles (A), clearances (B), shots blocked (C) and crosses blocked (D) per game.

\section{Discussion}

The aim of this study was to explore the effect of crowd removal (resulting from the COVID-19 pandemic) on goal scoring in elite soccer. Previous similar work has identified that the removal of crowds improved shooting performance in basketball (Moore \& Brylinsky, 1993). We aimed to establish if more goals were indeed being scored, and why. Firstly, we tested whether goal scoring was more frequent in the early games of the 2020/21 English Premier league season (which were played with no crowds). The previous four seasons

174 averaged between 2.6 and 2.9 goals per game (see Figure 1). The 2020/21 season averaged

1753.8 goals per game, a statistically significant increase. The main increase was observed in goals scored from within the penalty box (but outside the six-yard box) rather than short range (six-yard box) or long range (outside penalty area) goals. More goals appeared to be arising from open play and penalties, but not counter attacks or set pieces. 
Running head: FOOTBALL CROWDS

This manuscript has not been peer reviewed

179

180

181

182

183

184

185

186

187

188

189

190

191

192

193

194

195

196

197

198

199

200

201

202

203

204

205

206

207

208

209

It was broadly predicted that the increase in goal scoring might be related to a reduction is psychological pressure, which is known to disrupt the execution of highly attuned motor skills (Eysenck \& Wilson, 2016; Nieuwenhuys \& Oudejans, 2012; Payne et al., 2018). When exploring the performance data there was no clear evidence of this. There was no increase in indicators of attacking play (shots, dribbles and interceptions) that might suggest players had reduced fear of failure and were taking more risks. Additionally, there were only small differences in some indicators of skill execution (e.g. shooting accuracy) and no difference in others (e.g. passing accuracy and dribbling success). While it has been suggested that the presence of crowds can increase pressure and make players more risk averse (Wallace et al., 2005) and more prone to skill failure (Butler \& Baumeister, 1998), there was no real evidence that the contrary was true in this data set.

Somewhat unexpectedly, there was evidence that the increase in goal scoring could be related to a general reduction in the quality of defending. There were possible decrements in the number of tackles, number of clearances made, and number of crosses blocked per game, compared to previous seasons. This is alongside no discernible increase in attacking play or execution. Speculatively, this reduction in defensive performance could be related to motivational issues. While changes in attacking play (passing and shooting accuracy etc.) might be more skill dependent, metrics like tackles, clearances and blocks may be more affected by motivation and effort. Motivation and effort are factors which could be negatively affected by the loss of crowds (Strauss, 2002). However, more evidence of intervening mechanisms would be needed to test this possibility.

In summary, in this real-world data set we observed that the removal of crowds from Premier League soccer in 2020/21 has coincided with a substantial increase in goal scoring. In particular there was an increase in goals from penalties which may have reflected either 1) changes in the rules of how penalties are awarded due to changes in FIFA and UEFA regulations on handball, or (2) differences in the defending tactics observed. There are a range of effects that the lack of crowds might have on the performance of elite level athletes, such as motivation and arousal. Here we particularly focused on whether the removal of crowds might reduce pressure on soccer players. The in-game statistics did not suggest that there was any clear decrement to the execution of attacking skills, so did not support that the increase in goal scoring was related to reduced pressure. A better 
Running head: FOOTBALL CROWDS

This manuscript has not been peer reviewed

210

211

212

213

214

215

216

217

218

219

220

221

222

223

224

225

226

227

228

229

230

231

232

233

234

examination of the experience of players is needed to more fully answer this research

question. It is also important to bear in mind some of the other contextual factors that could influence performance, besides the removal of crowds. The preceding season finished late because of COVID-19 restrictions, and hence players had a very short off-season.

Additionally, general anxiety and uncertainty related to the wider pandemic situation may well affect the performance of some players. However, the current situation provided a rare opportunity to examine how crowds may affect elite sport and may provide a starting point for future experimental work that can more fully address intervening mechanisms.

\section{References}

Allen, M., Poggiali, D., Whitaker, K., Marshall, T. R., \& Kievit, R. A. (2019). Raincloud plots: A multi-platform tool for robust data visualization. Wellcome Open Research, 4. https://doi.org/10.12688/wellcomeopenres.15191.1

Baumeister, R. F. (1984). Choking under pressure: Self-consciousness and paradoxical effects of incentives on skillful performance. Journal of Personality and Social Psychology, $46(3), 610-620$.

Baumeister, R. F., \& Steinhilber, A. (1984). Paradoxical effects of supportive audiences on performance under pressure: The home field disadvantage in sports championships. Journal of Personality and Social Psychology, 47(1), 85-93. https://doi.org/10.1037/0022-3514.47.1.85

Beilock, S. L., \& Carr, T. H. (2001). On the fragility of skilled performance: What governs choking under pressure. Journal of Experimental Psychology: General, 130, 701725.

Boudreaux, C. J., Sanders, S. D., \& Walia, B. (2017). A Natural Experiment to Determine the Crowd Effect Upon Home Court Advantage. Journal of Sports Economics, 18(7), 737749. https://doi.org/10.1177/1527002515595842 
Running head: FOOTBALL CROWDS

This manuscript has not been peer reviewed

235

236

237

238

239

240

241

242

243

244

245

246

247

248

249

250

251

252

253

254

255

256

Butler, J. L., \& Baumeister, R. F. (1998). The trouble with friendly faces: Skilled performance with a supportive audience. Journal of Personality and Social Psychology, 75(5), 1213-1230. https://doi.org/10.1037/0022-3514.75.5.1213

Deutscher, C., Ötting, M., Langrock, R., Gehrmann, S., Schneemann, S., \& Scholten, H. (2018). Very Highly Skilled Individuals Do Not Choke Under Pressure: Evidence from Professional Darts. ArXiv:1809.07659 [Stat]. http://arxiv.org/abs/1809.07659

Downward, P., \& Jones, M. (2007). Effects of crowd size on referee decisions: Analysis of the FA Cup. Journal of Sports Sciences, 25(14), 1541-1545. https://doi.org/10.1080/02640410701275193

Epting, L., Riggs, K. N., Knowles, J. D., \& Hanky, J. J. (2011). Cheers vs. Jeers: Effects of audience feedback on individual athletic performance. North American Journal of Psychology, 13, 299-312.

Eysenck, M. W., \& Wilson, M. R. (2016). Sporting performance, pressure and cognition: Introducing attentional control theory: Sport. In D. Groome \& M. Eysenck (2nd ed). An introduction to applied cognitive psychology. (Pp. 329-350). London: Routledge.

Greer, D. L. (1983). Spectator Booing and the Home Advantage: A Study of Social Influence in the Basketball Arena. Social Psychology Quarterly, 46(3), 252-261. JSTOR. https://doi.org/10.2307/3033796

Harris, D. J., Vine, S. J., Eysenck, M. W., \& Wilson, M. R. (2019). To err again is human: Exploring a bidirectional relationship between pressure and performance failure feedback. Anxiety, Stress, \& Coping, 32(6), 670-678. https://doi.org/10.1080/10615806.2019.1643459 
Running head: FOOTBALL CROWDS

This manuscript has not been peer reviewed

257

258

259

260

261

262

263

264

265

266

267

268

269

270

271

272

273

274

275

276

277

278

279

280

Hickman, D. C., \& Metz, N. E. (2015). The impact of pressure on performance: Evidence from the PGA TOUR. Journal of Economic Behavior \& Organization, 116, 319-330. https://doi.org/10.1016/j.jebo.2015.04.007

Hill, D. M., Hanton, S., Matthews, N., \& Fleming, S. (2010). Choking in sport: A review. International Review of Sport and Exercise Psychology, 3(1), 24-39. https://doi.org/10.1080/17509840903301199

Jones, M. V., Bray, S. R., \& Lavallee, D. (2007). All the world's a stage: Impact of an audience on sport performers. Social Psychology in Sport, 103-113.

Jones, Marc V. (2003). Controlling Emotions in Sport. The Sport Psychologist, 17(4), 471486. https://doi.org/10.1123/tsp.17.4.471

Lakens, D. (2019). The Value of Preregistration for Psychological Science: A Conceptual Analysis. https://doi.org/10.31234/osf.io/jbh4w

Marcelino, R., Mesquita, I., Palao Andrés, J. M., \& Sampaio, J. (2009). Home Advantage in High-Level Volleyball Varies According to Set Number. Journal of Sports Science \& Medicine, 8(3), 352-356.

Moore, J. C., \& Brylinsky, J. A. (1993). Spectator Effect on Team Performance in College Basketball. Journal of Sport Behavior; Mobile, Ala., 16(2), 77-84.

New York Times. (2020). Why are NFL scores so high this season? https://www.nytimes.com/2020/10/11/sports/football/nfl-scores-high-points.html.

Nieuwenhuys, A., \& Oudejans, R. R. D. (2012). Anxiety and perceptual-motor performance: Toward an integrated model of concepts, mechanisms, and processes. Psychological Research, 76(6), 747-759. https://doi.org/10.1007/s00426-011-0384-x

Patil, I. (2018). Ggstatsplot: 'ggplot2' Based Plots with Statistical Details. CRAN. Retrieved from Https://Cran.r-Project.Org/Web/Packages/Ggstatsplot/Index.Html. 
Running head: FOOTBALL CROWDS

This manuscript has not been peer reviewed

281

282

283

284

285

286

287

288

289

290

291

292

293

294

295

296

297

298

299

300

301

302

303

Paulus, P. B. (1983). Group Influence on Individual Task Performance. In P. B. Paulus (Ed.), Basic Group Processes (pp. 97-120). Springer. https://doi.org/10.1007/978-1-46125578-9_5

Payne, K. L., Wilson, M. R., \& Vine, S. J. (2018). A systematic review of the anxiety-attention relationship in far-aiming skills. International Review of Sport and Exercise Psychology, O(0), 1-31. https://doi.org/10.1080/1750984X.2018.1499796

R Core Team. (2017). R: A language and environment for statistical computing. $R$ Foundation for Statistical Computing, Vienna, Austria. URL https://www.Rproject.org/.

Scheel, A. M., Tiokhin, L., Isager, P. M., \& Lakens, D. (2020). Why hypothesis testers should spend less time testing hypotheses [Preprint]. PsyArXiv. https://doi.org/10.31234/osf.io/vekpu

Strauss, B. (2002). Social facilitation in motor tasks: A review of research and theory. Psychology of Sport and Exercise, 3(3), 237-256. https://doi.org/10.1016/S14690292(01)00019-X

TalkSport.com. (2020). Premier League clubs on course to smash season goal record. https://talksport.com/football/769373/premier-league-goals-2020-21-recordcalvert-lewin-stats-son-grealish/.

Toma, M. (2017). Missed Shots at the Free-Throw Line: Analyzing the Determinants of Choking Under Pressure. Journal of Sports Economics, 18(6), 539-559. https://doi.org/10.1177/1527002515593779

Triplett, N. (1898). The Dynamogenic Factors in Pacemaking and Competition. The American Journal of Psychology, 9(4), 507-533. JSTOR. https://doi.org/10.2307/1412188 
Running head: FOOTBALL CROWDS

This manuscript has not been peer reviewed

304 Wallace, H. M., Baumeister, R. F., \& Vohs, K. D. (2005). Audience support and choking under

305 pressure: A home disadvantage? Journal of Sports Sciences, 23(4), 429-438.

306 https://doi.org/10.1080/02640410400021666

307 Zajonc, R. B. (1965). Social Facilitation. Science, 149(3681), 269-274. JSTOR.

308 